Methods A retrospective observational audit conducted in the cardiac arrhythmia department at Connolly Hospital Blanchardstown from July 2020 until February 2021 involving all current patients using one of the three remote cardiac monitoring systems Latitude, Medtronic or Merlin. Inclusion criteria were patients with an implanted ICD, LR or PM device in the past 10 years who had a clinically relevant transmission in the above time frame. Transmissions were collected retrospectively on the Heart Rhythm Ireland database. Reports were examined for clinically relevant events such as atrial arrhythmias, ventricular arrhythmias, any therapy induced (ATP or shock therapy), lead dysfunction, battery warning, and/or heart failure index above threshold. Time from transmission to intervention was recorded in days. Interventions included reviewing with the team, contacting the patient, scheduling an appointment, or no response noted. Data were analyzed with Microsoft excel.

Results Of 575 transmissions, 157 were classified as true events. Further categorized as 76 ventricular arrhythmias (mean response 4 days), 52 atrial arrhythmias (mean response 3.7 days), 39 heart failure alerts (mean response 2.1 days), 13 lead issues (mean response 1.1 days), and 4 battery warnings (mean response 0.3 days).

Conclusion RCDM has undoubtedly enhanced the care of patients, however without standardized protocols in place irregularities and mismanagement of cases may occur. This audit highlights significant variations in mean response time with potential to affect patient outcomes. Thus, a recommendation for a national standard for all cardiac units in Ireland stating desired timelines whereby a specific event should be managed and an order of priority for alert transmissions. To conclude, there is still a lot to be established for the realistic application of RCDM in order to fully reap the rewards from modern advancement in technology.

\section{INFLUENCE OF ROUTINE CARDIAC RHYTHM ASSESSMENT IN THE LONG-TERM MANAGEMENT OF CHANNELOPATHY PATIENTS}

1,2HM Sulaiman, ${ }^{1} \mathrm{R}$ Hackett, ${ }^{1} \mathrm{M}$ Hogg, ${ }^{1} \mathrm{E}$ Banks, ${ }^{1} \mathrm{~A}$ Muir. ${ }^{1}$ Belfast Health and Social Care Trust, UKi ${ }^{2}$ Cormac Fellowship, UK

10.1136/heartjn|-2021-ICS.27

Introduction and Aim There are no definitive European or American guidelines for the routine follow-up of patients with channelopathies. In the Northern Ireland Inherited Cardiovascular conditions (NI ICC) service, we routinely organise repeat cardiac investigations including 24 hour tape monitor in all patients diagnosed with or suspected of a channelopathy, irrespective of their symptoms. This audit reviews our practice to determine if these influence management or outcome in patients with channelopathies.

Methods Data was retrospectively collected on all patients attending a single consultant at the NI ICC service between April-December 2019. We selected new and review patients with:

- a confirmed diagnosis of a channelopathy [Brugada syndrome (BrS) or LQT syndrome (LQTS)]

- undergoing screening for channelopathy (BrS or LQTS) due to family history or suspicious ECG

- Screening of survivors OOHCA (Out of hospital cardiac arrest).
Patient demographics, symptoms, family history, genetic results and follow up investigation results were collected.

Results 112 patients undergoing channelopathy assessment [60\% female, $43 \pm 17$ years]. 84 had a confirmed diagnosis of a channelopathy (LQTS 55 (49\%) or BrS 29 (26\%)). 18 were new patients undergoing screening due to a family history (LQTS $\mathrm{n}=8(7 \%)$ or $\mathrm{BrS} n=10(9 \%))$ and 6 new patients with suspicious ECG changes (LQTS $n=5$ (4\%) or BrS $n=1$ $(1 \%))$. Four patients underwent assessment following an OOHCA (4\%). A total of $55(50 \%)$ patients reported cardiac symptoms at review [palpitations (28), pre-syncope (13) or syncope (14)]. 26 had a cardiac implantable device in situ suitable for interrogation (14 ICD, 1 PPM and 11 ILR) and the rest of the cohort underwent Holter analysis (36 still awaiting appointment, 6 did not attend and one died pretest). Clinical management was altered by rhythm assessment in 7 of $69(10 \%)$ cases (alteration of medication (3), ICD recommendation (3) and referral for EP study (1) [table 1] but of these, only 5 had reported symptoms. Routine Holter monitoring identified a life threatening rhythm disturbance in only 1 individual. A total of 2 patients died during follow up (1 non-cardiac whilst 1 likely arrhythmic death).

Conclusion In our selected channelopathy patients, we demonstrated that the yield of routine monitoring arrangement is low at $10 \%$ despite $50 \%$ of patients reporting concerning cardiac symptoms. A large proportion of our cohort continue to await rhythm assessment due to delays in scheduling from the Covid-19 pandemic but 93\% have had no change in

Abstract 27 Table 1 Rhythm disturbances identified in follow up of channelopathy patients

\begin{tabular}{|c|c|c|c|c|c|}
\hline & $\begin{array}{l}\text { Diagnosis } \\
\text { Gene } \\
\text { testing } \\
\text { result }\end{array}$ & $\begin{array}{l}\text { Monitoring } \\
\text { method }\end{array}$ & Symptoms & $\begin{array}{l}\text { Rhythm } \\
\text { disturbance }\end{array}$ & $\begin{array}{l}\text { Alteration to } \\
\text { treatment }\end{array}$ \\
\hline 1 & $\begin{array}{l}\text { OOHCA } \\
\text { Query } \\
\text { LQTS } \\
\text { Gene } \\
\text { negative }\end{array}$ & $I C D$ & yes syncope & $\begin{array}{l}\text { NCT/inappropriate } \\
\text { shock }\end{array}$ & $\begin{array}{l}\text { BBlocker } \\
\text { changed to } \\
\text { verapamil }\end{array}$ \\
\hline 2 & $\begin{array}{l}\text { OOHCA } \\
\text { Query BrS } \\
\text { Gene } \\
\text { negative }\end{array}$ & $I C D$ & none & NCT & $\begin{array}{l}\text { Medication } \\
\text { change }\end{array}$ \\
\hline 3 & $\begin{array}{l}\text { LQTS } \\
\text { KCNQ1 }\end{array}$ & ILR & $\begin{array}{l}\text { yes palpitations } \\
\& \text { pre-syncope }\end{array}$ & $\mathrm{AF}$ & anticoagulation \\
\hline 4 & $\begin{array}{l}\text { Screening } \\
\text { LQTS } \\
\text { No gene } \\
\text { testing }\end{array}$ & ILR & $\begin{array}{l}\text { yes palpitations, } \\
\text { pre-syncope \& } \\
\text { syncope }\end{array}$ & SVT & EPS/ablation \\
\hline 5 & $\begin{array}{l}\text { LQTS } \\
\text { KCNQ1 }\end{array}$ & Holter & none & $\begin{array}{l}22 \% \text { VEs, } 7 \text { beats } \\
\text { NSVT }\end{array}$ & ICD offered \\
\hline 6 & $\begin{array}{l}\text { LQTS } \\
\text { KCNQ1 }\end{array}$ & Holter & yes palpitations & PAT & $\begin{array}{l}\text { BBlocker } \\
\text { commenced }\end{array}$ \\
\hline 7 & $\begin{array}{l}\text { BrS } \\
\text { SCN5a } \\
\text { VUS }\end{array}$ & Holter & yes palpitations & $\begin{array}{l}\text { Atrial PACs, NCT, } \\
\text { conduction } \\
\text { disease, NSVT }\end{array}$ & $\begin{array}{l}\text { ICD offered and } \\
\text { declined }\end{array}$ \\
\hline
\end{tabular}

*OOHCA: Out of hospital cardiac arrest, LQTS= LQT syndrome, BrS: Brugada syndrome BBlocker: beta-blocker, NCT: narrow complex tachycardia, AF: atrial fibrillation, SVT: supraventricular tachycardia, NSVT: non-sustained ventricular tachycardia, PAT: paroxysmal atrial tachycardia, PACs: paroxysmal atrial complex, VE: ventricular ectopic, ILR: implantable loop recorder, ICD: Implantable cardiac defibrillator, EPS: EP study. 
management to date. As of March 2021 mortality was only $1 \%$ with just a single patient dying of a suspected dysrhythmia. There is a lack of international guideline on timing of follow up investigation in routine management of channelopathies, but our cohort suggests that routine Holter monitoring in asymptomatic LQTS and BrS does not significantly alter sudden cardiac death (SCD) risk management. We educate our ICC channelopathy patients' to report their symptoms to facilitate prompt rhythm assessment, and given pressures on current health systems, perhaps focusing on these symptomatic patients would be an appropriate use of resources.

\section{OUR LEFT BUNDLE BRANCH PACING EXPERIENCE: A SINGLE CENTRE STUDY}

R Walsh, F Kehoe, S Frohlich, N Murphy, I Lyne. Beacon Hospital, Dublin, Ireland

\subsection{6/heartjnl-2021-ICS.28}

Background Chronic ventricular pacing results in dyssynchronous ventricular activation and may result in pacing-induced cardiomyopathy. Conduction system pacing (CSP) allows for physiologic ventricular activation. Left bundle branch pacing (LBBp) has emerged in recent time as an alternative to Hisbundle pacing. It offers the physiological ventricular activation while avoiding the difficulty in targeting the His-bundle and maintaining stable long term lead parameters. Here we describe our experience LBBp.

Objective To describe the LBBp experience and compare the learning curve associated with LBBp to that described with His-bundle pacing.

Methods This study is a retrospective and observational study. Our patient cohort of 90 patients was collected between November 2019 to March 2021. We included all patients who underwent LBBp in this period and examined them at 2 and 6 months post operatively. We further divided these patients into four quartiles to further examine our learning curve. They were examined on age, gender, diagnosis, co-morbidities, NYHA score, tricuspid regurgitant velocity, LVEF, LVEDd, procedure time, fluoroscopy time, and complications. We examined pre- and post- QRS, pre- and post- QRS axis, selective LBBp at implant and follow up, and implant pacemaker parameters and at follow-up. Data was collected and analysed.

Results A total of $64.5 \%$ of patients were male, mean age was 76 years. $15.1 \pm 37 \%$ were LBBB with $\mathrm{HF}, 51.1 \pm \%$ were AVN block/AF with AVN ablation, and 30.2\% were sick sinus syndrome. The majority of patients were NYHA I or II. The mean EF preimplant was $48.3 \%$. Average pre- and immediate post- QRS was $126.7 \mathrm{~ms}$ and $126.4 \mathrm{~ms}$ respectively. At a mean follow up of 5 months QRS average was $119.3 \mathrm{~ms}$. Mean thresholds at follow up were $0.73 \pm 0.35 \mathrm{mV}, 0.72 \pm 0.22 \mathrm{mV}$, and $0.8 \pm 0.27 \mathrm{mV}$ at implant, 2 months, and 6 months respectively. Mean procedure time was $71 \pm 31.9$ minutes, with a mean fluoroscopy time of $11.7 \pm 8.6$ minutes. One patient required lead revision with displacement from the interventricular septum, one patient had a mild mediastinal bleed requiring transfusion, and 3 patients that failed LBBp insertion and were converted to standard techniques. No septal perforation, tricuspid valve injury, AV fistula or other pacemaker complication occurred. No complications were seen during follow-up. Conclusion Left bundle branch pacing offers a potential improvement on His-bundle pacing. Thresholds at implant were considerably lower, remained stable during follow-up, and sensing was improved compared to His-bundle pacing. Procedure time reduced as our experience grew, this varied with type of device inserted, as well as fluoroscopy time. Left bundle branch pacing is accessible with a comparable learning curve to His-bundle pacing. However, further large multicentre studies are needed to evaluated left bundle branch pacing further.

\section{THE ASSOCIATION BETWEEN NOVEL ST2, BNP, ATRIAL FIBRILLATION AND HEART FAILURE}

K Al-Wahaibi, I Khan, M Smith, T Leong. Hermitage Medical Clinic, Dublin, Ireland

\subsection{6/heartjnl-2021-ICS.29}

Background/Introduction ST2, a novel marker of fibrosis has been proposed as a novel biomarker for heart failure. There is paucity of data suggesting its association with Atrial Fibrillation (AF), in particular, with regards to the its independent effect after adjustment for clinical factors and traditional biomarkers such as BNP. There is increasing evidence that inflammation and fibrosis are important players in the pathogenesis of AF, the most common arrhythmia that is associated with considerable morbidity. Purpose We sought to examine the association of ST2 with AF and its possible incremental value in combination with traditional biomarkers already used in routine clinical practice such as BNP.

Methods Unselected patients presenting to a Cardiology service who had BNP for clinical reasons, concomitantly had ST2 sent. These patients included those with heart failure, acute coronary syndromes and AF, as well as patients attending cardioversion and cardiac catheterisation. The association between ST2, BNP and clinical factors was examined. ST2 was examined in tertiles as its distribution was highly skewed. Raised BNP was defined as usual $(\geq 100 \mathrm{pg} / \mathrm{ml})$.

Results Of the 619 patients, the mean age was 69 years and $66 \%$ were male. The prevalence of co-morbidities were: Coronary heart disease - CHD (41\%), Atrial Fibrillation - AF (30\%), Heart Failure - HF (20\%), Chronic Kidney Disease CKD (23\%). The mean eGFR was $68 \mathrm{ml} / \mathrm{h}$ and the mean LV ejection fraction was 55\%. Both ST2 and BNP levels were significantly higher in patients with heart failure, CKD and AF. Mean levels of ST2 were (in $\mathrm{ng} / \mathrm{ml}$ ): HF vs no HF (65 vs. $38, \mathrm{p}=0.0001)$ and in CKD vs. no CKD (49 vs. $41, \mathrm{p}=$ 0.001 ), CAD vs no CAD (43 vs. $42, p=0.3$ ). Mean levels of $\mathrm{BNP}$ were (in $\mathrm{pg} / \mathrm{ml})$ : $\mathrm{HF}$ vs no $\mathrm{HF}$ (579 vs. $131, \mathrm{p}=$ $0.0001)$, CKD vs. no CKD (379 vs. $173, \mathrm{p}=0.0001)$, CAD vs. no CAD (239 vs. $206, p=0.5)$. In patients with $\mathrm{AF}$, levels of both ST2 and BNP were higher, as were their mean ages

\begin{tabular}{|c|c|c|c|}
\hline \multirow[t]{2}{*}{$\begin{array}{l}\text { Abstract } 29 \text { Tabl } \\
\text { and AF }\end{array}$} & \multicolumn{3}{|c|}{ Comparison between patients without $\mathrm{AF}$} \\
\hline & No AF & AF & P value \\
\hline Age in years (SD) & $67(10)$ & $75(9)$ & $<0.0001$ \\
\hline Male sex & $65 \%$ & $69 \%$ & 0.44 \\
\hline \multicolumn{4}{|c|}{ Comorbidities/Risk Factors } \\
\hline Chronic heart failure & $13 \%$ & $36 \%$ & $<0.0001$ \\
\hline Chronic kidney disease & $18 \%$ & $34 \%$ & 0.003 \\
\hline Coronary heart disease & $46 \%$ & $29 \%$ & 0.001 \\
\hline $\operatorname{LVEF}(\mathrm{SD})$ & $65 \%(13 \%)$ & $53 \%(11 \%)$ & 0.005 \\
\hline \multicolumn{4}{|l|}{ Biomarkers } \\
\hline $\mathrm{BNP}(\mathrm{pg} / \mathrm{ml})$ & 158 & 370 & $<0.0001$ \\
\hline $\mathrm{ST} 2(\mathrm{ng} / \mathrm{ml})$ & 40 & 50 & $<0.0001$ \\
\hline hs-Tnl (ng/L) & 454 & 689 & 0.03 \\
\hline Creatinine $(\mu \mathrm{mol} / \mathrm{L})$ & 90 & 108 & $<0.0001$ \\
\hline eGFR $(\mathrm{mL} / \mathrm{min} / 1.73 \mathrm{~m} 2)$ & 67 & 60 & $<0.0001$ \\
\hline
\end{tabular}

